\title{
A gene expression study of dorso-ventrally restricted pigment pattern in adult fins of Neolamprologus meeli, an African cichlid species
}

\author{
Ehsan Pashay Ahi ${ }^{1}$, Kristina M Sefc ${ }^{1}$ \\ ${ }^{1}$ Institute of Zoology, Universitätsplatz 2, Universität Graz, Graz, Austria \\ Corresponding Author: Ehsan Pashay Ahi \\ Email address: epa1@hi.is
}

Fish color patterns are among the most diverse phenotypic traits found in the animal kingdom. Understanding the molecular and cellular mechanisms that control in chromatophore distribution and pigmentation underlying this diversity is a major goal in developmental and evolutionary biology, which has predominantly been pursued in the zebrafish model system. Here, we apply results from zebrafish work to study a naturally occurring color pattern phenotype in the fins of an African cichlid species from Lake Tanganyika. The cichlid fish Neolamprologus meeli displays a distinct dorsal color pattern, with black and white stripes along the edges of the dorsal fin and of the dorsal half of the caudal fin, corresponding with differences in melanophore density. To elucidate the molecular mechanisms controlling the differences in dorsal and ventral color patterning in the fins, we quantitatively assessed the expression of 15 candidate target genes involved in adult zebrafish pigmentation and stripe formation. For reference gene validation, we screened the expression stability of seven widely expressed genes across the investigated tissue samples and identified tbp as appropriate reference. Relative expression levels of the candidate target genes were compared between the dorsal, striped fin regions and the corresponding uniform, grey-colored regions in the anal and ventral caudal fin. Dorsoventral expression differences, with elevated levels in both white and black stripes, were observed in two genes, the melanosome protein coding gene pmel and in igsf11, which affects melanophore adhesion, migration and survival. Next, we predicted potential shared upstream regulators of pmel and igsf11. Testing the expression patterns of six predicted transcriptions factors revealed dorso-ventral expression difference of irfland significant, negative expression correlation of irf1 with both pmel and igsf11. Based on these results, we propose pmel, igsf11 and irf1 as likely components of the genetic mechanism controlling distinct dorso-ventral color patterns in N. meeli fins. 


\section{A gene expression study of dorso-ventrally restricted}

\section{2 pigment pattern in adult fins of Neolamprologus meeli, an}

3 African cichlid species

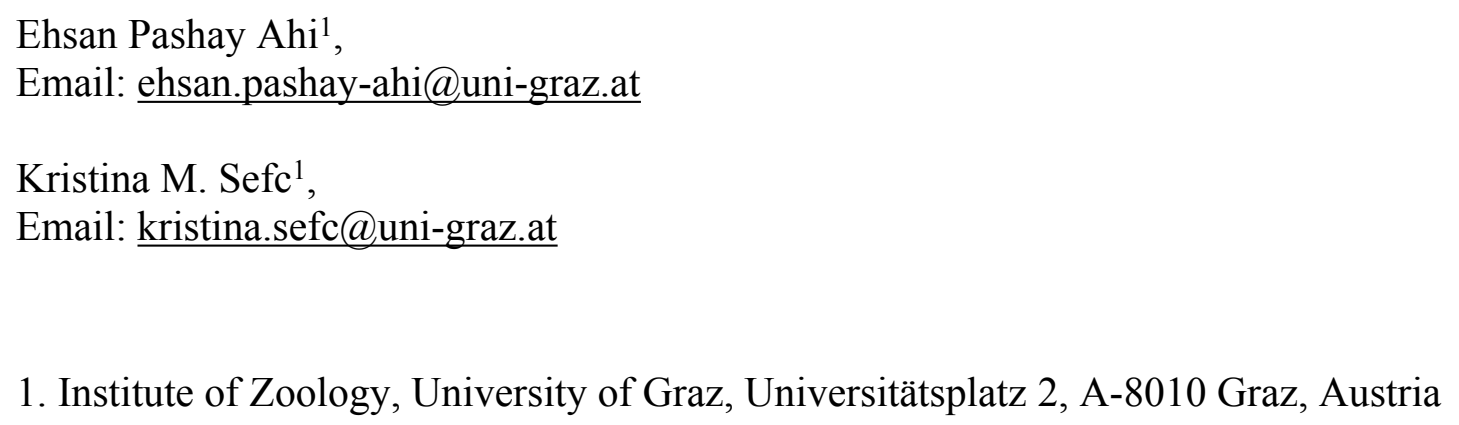

1. Institute of Zoology, University of Graz, Universitätsplatz 2, A-8010 Graz, Austria

\section{Abstract}

Fish color patterns are among the most diverse phenotypic traits found in the animal kingdom. Understanding the molecular and cellular mechanisms that control in chromatophore distribution and pigmentation underlying this diversity is a major goal in developmental and evolutionary biology, which has predominantly been pursued in the zebrafish model system. Here, we apply results from zebrafish work to study a naturally occurring color pattern phenotype in the fins of an African cichlid species from Lake Tanganyika. The cichlid fish Neolamprologus meeli displays a distinct dorsal color pattern, with black and white stripes along the edges of the dorsal fin and of the dorsal half of the caudal fin, corresponding with differences in melanophore density. To elucidate the molecular mechanisms controlling the differences in dorsal and ventral color patterning in the fins, we quantitatively assessed the expression of 15 candidate target genes involved in adult zebrafish pigmentation and stripe formation. For reference gene validation, we screened the expression stability of seven widely expressed genes across the investigated tissue samples and identified tbp as appropriate reference. Relative expression levels of the candidate target genes were compared between the dorsal, striped fin regions and the corresponding uniform, grey-colored regions in the anal and ventral caudal fin. Dorso-ventral expression differences, with elevated levels in both white and black stripes, were observed in two 
32 adhesion, migration and survival. Next, we predicted potential shared upstream regulators of pmel and igsf 11 . Testing the expression patterns of six predicted transcriptions factors revealed dorso-ventral expression difference of $\mathrm{irfl}$ and significant, negative expression correlation of $\mathrm{irfl}$ with both pmel and igsf11. Based on these results, we propose pmel, igsfl1 and irfl as likely components of the genetic mechanism controlling distinct dorso-ventral color patterns in $N$. meeli fins.

\section{Introduction}

The mechanisms underlying the formation and diversification of integumental colour patterns in vertebrates have always been a fascinating subject of biological research. Much of the scientific attraction to colour patterns, besides an appreciation of their innate beauty, is due to their enormous diversity and rapid evolution, their crucial roles in mate choice and camouflage, and the comparative easiness with which the colour pattern phenotypes can be observed and scored (Hoekstra 2006; Mills \& Patterson 2009). The extensive diversity of vertebrate integumental colour patterns arises from variation in migration, organization and differentiation of pigment cells, which themselves originate from neural crest-derived precursor cells during embryonic development (Kelsh et al. 2009; Bronner \& LeDouarin 2012). It comes with no surprise that teleost fishes as the largest and most diverse group of vertebrates exhibit the highest complexity and diversity in pigmentation patterns. Fish possess the highest number of pigment classes among vertebrates, which are contained in several types of pigment cells (chromatophores), i.e. melanophores (black pigment), erythrophores and xanthophores (yellow-red pigments), cyanophores (blue pigment) and light reflecting iridophores/leucophores (silvery white) (Fujii 2000; Lynn Lamoreux et al. 2005; Kelsh et al. 2009). The unrivalled diversity of piscine colours and patterns has been attributed to fundamental genetic changes, such as the whole-genome duplication in the teleost lineage providing additional copies of pigmentation genes, and the retention of duplicated pigmentation genes (lost in other vertebrates) from earlier genome duplications in the vertebrate lineage (Braasch et al. 2008, 2009). Despite the differences, genetic studies in fish and tetrapod models, particularly using zebrafish, mouse and chicken mutants, have revealed conservation in some patterning mechanisms such as genes involved in 
61 migration and formation of melanophores (Lister et al. 2001; Kelsh 2004; Hoekstra 2006; Mills

62 \& Patterson 2009; Kelsh et al. 2009).

63 Pigment patterning is also highly influenced by environmental cues and cellular interactions

64 between the chromatophores (Leclercq et al. 2009). Studies in zebrafish showed that the

65 presence of only one type of chromatophore, and the absence of other types, leads to a uniform distribution of the chromatophore throughout the skin without specific pattern (Singh \& Nüsslein-Volhard 2015). The interactions between chromatophores can be complex; for instance, iridophores suppress melanophore survival locally but promote it at a longer distance (Frohnhöfer et al. 2013). Among the extensive collection of colour patterns, a frequent motif in teleost fish is the organization of pigment cells along dorso-ventral or anterior-posterior body axes into stripes (Maan \& Sefc 2013; Singh \& Nüsslein-Volhard 2015). So far, several genes have been shown to be involved in stripe formation (Singh \& Nüsslein-Volhard 2015). Intriguingly, stripes can appear predominantly or exclusively in specific body compartments and/or fins, and little is known about the molecular mechanisms that restrict pattern formation to specific regions. Moreover, fin and body stripe formation are controlled by different mechanisms in zebrafish, and while body stripe formation has been extensively studied, much less is known about the mechanisms operating in fins (Singh \& Nüsslein-Volhard 2015). However, given that fin pattern variation contributes significantly to the phenotypic diversity of teleost fish, an increased understanding of its molecular background is highly desirable.

In this study, we quantitatively assess the expression of a set of genes involved in adult zebrafish pigmentation and stripe formation (Table 1) in distinctly coloured fin regions of a cichlid fish, Neolamprologus meeli, endemic to the Lake Tanganyika in Africa. The study fish displays a contrasting pattern of black and white stripes in its dorsal and caudal fins (see Fig. 1A) which emerges during the juvenile stage and is maintained throughout adulthood. The phenotype resembles dorso-ventrally distinct pigment patterns observed not only in fishes but also in evolutionary distant mammalian and avian species (Fig. 1B-C) (Metallinos et al. 1998; Matsushima et al. 2002; Baxter et al. 2004; Miwa et al. 2007; Hauswirth et al. 2012; Andersson et al. 2013; Kinoshita et al. 2014; Li et al. 2015).

On the cellular level, the distinct dorso-ventral fin patterning could involve differences in the number of melanophores and iridophores, or in the case of melanophores, changes in size and number of melanosomes (the pigmented organelles in melanophores). We hypothesized that 
92 variation in the arrangement and abundance of chromatophores and in melanosome traits of the 93 adult fish would be reflected in the expression levels of genes involved in stripe formation and

94 95 96 97 98 adult pigmentation. The identification of such differentially expressed genes will provide a foundation for further understanding of the molecular mechanisms underlying pigment motifs along body axes. Furthermore, mechanisms of stripe formation, particularly those involving iridophore-derived patterning, in the zebrafish body appeared to be different from those in fins (Singh \& Nüsslein-Volhard 2015). Hence, our study will shed light on the role of genes, which control the formation of body stripes in adult zebrafish, in the patterning of N. meeli fins. In our study, we first characterized the colour pattern phenotype by determining the distribution of melanophores in each fin region, and verifying the presence of iridophores based on the expression of an irodophore-specific marker gene. Next, we investigated the expression patterns of candidate genes in the differently coloured regions of the different fins. Finally, we examined the expression patterns of predicted potential upstream regulators of two differentially expressed target genes. By identifying dorso-ventrally distinct expression of two target genes and one potential shared transcription factor, our work suggests potential components of the mechanism controlling dorsally restricted stripe formation in N. meeli.

\section{Methods}

\section{Fin sampling and melanophore counting}

Four captive bred, adult individuals of $N$. meeli, two males and two females, were used in this study. The size of the fish was between $7-10 \mathrm{~cm}$ and their fins looked intact. The fishes did not show sex dependent differences or individual variation in their stripe patterns. Prior to the experiments, the fish were transferred to separate aquaria and fed on identical diets for two weeks. To obtain fin tissue biopsies, the fish were anesthetized in water containing 0.04 gram per litre of MS-222 and parts of their dorsal fin (D), anal fin (A), and dorsal and ventral parts of their caudal fin $(\mathrm{Cd}$ and $\mathrm{Cv})$ were cut under a stereomicroscope (the clipped fin areas are specified by blue dashed squares in Fig. 1A). From each of the cut fin tissues, a piece was dissected and immersed in $0.5 \mathrm{mg} / \mathrm{ml}$ epinephrine solution (Sigma No.E4375) for $60 \mathrm{~min}$ in order to aggregate the melanosomes. The remaining fin tissue was dissected carefully based on its distinct colours (specified with red circles in Fig. 1A), and each piece was immersed in RNAlater (Qiagen) and 
122 stored frozen until RNA isolation. Throughout the paper, the individual fin tissues investigated in

123 the study are addressed as "fin regions" and identified by fin type and a number referring to

124 location, such that, for instance, A-1 stands for the distal region of the anal fin, A-2 identifies the

125 middle region and A-3 the proximal region (Fig. 1A). Anatomically equivalent fin regions are

126 grouped into distal, middle and proximal "classes of fin regions" (e.g., the distal class consists of

127 the regions D-1, Cd-1, Cv-1 and A-1; Fig. 1A).

128 Photographs of the epinephrine treated fin tissues were taken with a camera mounted on a

129 stereomicroscope (eyepiece micrometre x20, Leica). For each fin region, melanophores were

130 counted in four inter-ray fin tissue sections and the area of the inter-ray tissue was measured

131 based on pixel counts. Melanophore density in each fin region was calculated as number of

132 melanophores $/ \mathrm{mm}^{2}$. Anaesthesia and fin biopsies were performed under permit number

133 BMWFW-66.007/0013-WF/V/3b/2016 issued by the Federal Ministry of Science, Research and

134 Economy of Austria.

135

\section{RNA isolation and cDNA synthesis}

137 Tissue samples of the individual fin regions (see above) were transferred from RNAlater to tubes

138 containing TRI Reagent (Sigma) and $1.4 \mathrm{~mm}$ ceramic spheres, and homogenized by FastPrep-24

139 Instrument (MP Biomedicals, Santa Ana, CA, USA). RNA was extracted according to

140 manufacturer's Trizol protocol and dissolved in 30 $\mu 1$ RNase-free water. RNA samples were

141 treated with DNase (New England Biolabs) to remove contaminating DNA. RNA concentration

142 was measured by spectrophotometry using a Nanophotometer (IMPLEN GmbH, Munich,

143 Germany). The quality of the RNA samples was evaluated in a R6K ScreenTape System on an

144 Agilent 2200 TapeStation (Agilent Technologies) to ensure that the integrity number (RIN) of all

145 samples was higher than 7. cDNA was prepared from 1000 ng of RNA using the High Capacity

146 cDNA Reverse Transcription kit (Applied Biosystems), according to the manufacturer's protocol.

147 Negative controls, i.e. reactions without addition of reverse transcriptase (-RT samples), were

148 prepared to confirm the absence of genomic DNA. cDNA was diluted 1:3 times in nuclease-free

149 water for further use in quantitative real-time PCR.

150

151 Gene selection, Primer design and real-time qPCR 
152 To validate suitable reference genes for accurate expression analysis, we selected 7 genes

153 expressed in a variety of tissues and frequently used as reference gene candidates in qPCR 154 studies of teleost fishes (Table S1) (Tang et al. 2007; Fernandes et al. 2008; Olsvik et al. 2008;

155 Small et al. 2008; Zheng \& Sun 2011; Yang et al. 2013; Ahi et al. 2013). In addition, we 156 selected 15 target genes that are known to be involved in adult pigmentation and/or stripe 157 formation in zebrafish (Table 1 and Table S1). Later, we extended our expression analyses to 6 158 additional candidate genes, which were predicted as potential upstream regulators of two 159 differentially expressed genes in our study (Table S1).

160 The qPCR primers were designed within sequences conserved across African cichlids, based on 161 recently released transcriptome data from a distantly related species, Oreochromis niloticus, and 162 a closely related species from Lake Tanganyika, Neolamprologus brichardi (Brawand et al. 163 2014). The sequence alignment was conducted using CLC Genomic Workbench, version 7.5 164 (CLC Bio, Aarhus, Denmark) and locations overlapping the exon boundaries of the genes were 165 determined based on the Nile Tilapia annotated genome sequences in the Ensembl database 166 (http://www.ensembl.org/Oreochromis_niloticus). The qPCR Primers were designed on exon 167 boundaries of the conserved regions using Primer Express 3.0 software (Applied Biosystems, 168 Foster City, CA, USA) and checked for self-annealing, hetero-dimers and hairpin structures with 169 OligoAnalyzer 3.1 (Integrated DNA Technology) (Table S1).

170 Real-time PCR was performed in 96 well-PCR plates on an ABI 7500 real-time PCR System 171 (Applied Biosystems) using Maxima SYBR Green/ROX qPCR Master Mix (2X) as 172 recommended by the manufacturer (Thermo Fisher Scientific, St Leon-Rot, Germany). Each 173 biological replicate was run in duplicate together with no-template control (NTC) in each run for 174 each gene and the experimental set-up per run followed the preferred sample maximization 175 method (Hellemans et al. 2007). The qPCR was run with a $2 \mathrm{~min}$ hold at $50^{\circ} \mathrm{C}$ and a $10 \mathrm{~min}$ hot 176 start at $95^{\circ} \mathrm{C}$ followed by the amplification step for 40 cycles of $15 \mathrm{sec}$ denaturation at $95^{\circ} \mathrm{C}$ and $1771 \mathrm{~min}$ annealing/extension at $60^{\circ} \mathrm{C}$. A dissociation step $\left(60^{\circ} \mathrm{C}-95^{\circ} \mathrm{C}\right)$ was performed at the end 178 of the amplification phase to identify a single, specific product for each primer set (Table S1).

179 Primer efficiency values (E) were calculated with the LinRegPCR v11.0 programme 180 (http://LinRegPCR.nl) (Ramakers et al. 2003) analysing the background-corrected fluorescence 181 data from the exponential phase of PCR amplification for each primer-pair and those with E less 182 than 0.9 were discarded and new primers designed (Table S1). 
184 Data analysis

185 Three different ranking algorithms, BestKeeper (Pfaffl et al. 2004), NormFinder (Andersen et al. 186 2004) and geNorm (Vandesompele et al. 2002), were employed to identify the most stably 187 expressed reference genes. The standard deviation (SD) based on Cq values of the fin regions 188 was calculated by BestKeeper to determine the expression variation for each reference gene. In 189 addition, BestKeeper determines the stability of reference genes based on correlation to other

190

191

192

193

194

195

196

197

198

199

200

201

202

203

204

205

206

207

208

209

210

211

212

213 candidates through calculation of BestKeeper index (r). GeNorm measures mean pairwise variation between each gene and other candidates, the expression stability or $M$ value, and it excludes the gene with the highest $M$ value (least stability) from subsequent analysis in a stepwise manner. NormFinder identifies the most stable genes (lowest expression stability values) based on analysis of the sample subgroups and estimation of inter- and intra-group variation in expression levels (Ahi et al. 2013; Pashay Ahi et al. 2016).

The $\mathrm{Cq}$ values of the best ranked reference genes was used as $\mathrm{Cq}_{\text {reference }}$ in the $\Delta \mathrm{Cq}$ calculations. For the analysis of the qPCR data, the difference between Cq values $(\Delta \mathrm{Cq})$ of the target genes and the selected reference gene was calculated for each target gene; $\Delta \mathrm{Cq}_{\text {target }}=\mathrm{Cq}_{\text {target }}-\mathrm{Cq}$ reference. All samples were then normalized to the $\Delta \mathrm{Cq}$ value of a calibrator sample to obtain a $\Delta \Delta \mathrm{Cq}$ value $(\Delta \mathrm{Cq}$ target $-\Delta \mathrm{Cq}$ calibrator $)$. For comparisons of gene expression involving all three classes of fin regions, one biological replicate of D-3 was arbitrarily chosen as calibrator sample. For comparisons restricted to anatomically equivalent fin regions, one biological replicate of D1, D-2 and D-3 served as calibrator for proximal, middle and distal fin region samples, respectively. Relative expression quantities (RQ) were calculated based on the expression level of the calibrator sample ( $\mathrm{E}^{-\Delta \Delta \mathrm{Cq}}$ ) (Pfaffl 2001). A two-way ANOVA followed by post hoc Tukey's HSD test was implemented for each target gene to compare RQ values among fins (averaged across regions) and fin regions. To assess similarities in the expression patterns of the target genes, Pearson correlation coefficients $(r)$ were calculated in R (http://www.r-project.org). To identify the potential upstream regulators, we performed motif enrichment analysis on $1 \mathrm{~kb}$ promoter sequences of two differentially expressed genes, based on the annotated genome of the Nile tilapia (Flicek et al. 2013) using three programs: MEME (Bailey et al. 2009), SCOPE (Carlson et al. 2007) and XXmotif (Luehr et al. 2012). We retained the enriched motifs that were present in both promoters and screened for potential transcription factor (TF) binding sites using 
214 STAMP (Mahony \& Benos 2007), with the motif position weight matrices (PWMs) retrieved

215 from the TRANSFAC database (Matys et al. 2003).

216

217 Results

218 Characterization of melanophore distribution in the fin regions

219 Comparisons of melanophore density and gene expression patterns were conducted between

220 anatomically comparable regions of the dorsal, caudal and anal fins; i.e. either among the total

221 areas cut from each fin (e.g. D-1 + D-2 + D-3 for the dorsal fin), or separately within each of the

222 corresponding fin region classes; the distal fin regions (D-1, Cd-1, Cv-1 and A-1); the middle fin

223 regions (D-2, Cd-2, Cv-2 and A-2); and the proximal fin regions (D-3, Cd-3, Cv-3 and A-3).

224 Expression comparisons between different classes of fin regions were avoided, because, given

225 the different histological properties of distinct anatomical fin regions along proximal-distal axis,

226 gene expression differences between non-analogous regions could arise for various reasons not

227 associated with colour patterning.

228 Melanophore density was significantly higher in the black distal regions of the dorsal fin and

229 dorsal part of the caudal fin (D-1 and Cd-1) than in their dark grey ventral counterparts, A-1 and

$230 \mathrm{Cv}-1$ (Fig. 2C). The white dorsal middle regions (D-2 and Cd-2) contained almost no

231 melanophores, whereas melanophore densities were intermediate in their grey ventral

232 counterparts, A-2 and Cv-2, and finally the most proximal regions in all the fins had almost

233 similar numbers of melanophores (Fig. 2C). Melanophore density clearly corresponded with the

234 impression of darkness/lightness of the investigated fin regions. Additionally, the white colour of

235 D-2 and Cd-2 regions appeared to be the result of both melanophore absence and an

236 accumulation of white reflecting iridophores (Fig. 2B). Interestingly, total melanophore numbers

237 summed across fin regions did not differ between fins (Fig. 2D). This indicates that the different

238 fin patterns result from variation in the distribution and perhaps also pigmentation of a constant

239 number of melanophores. In other words, aggregation of melanophores in the black regions and

240 their absence in white regions determines the dorsal stripes, whereas in their ventral counterpart

241 regions, the same number of melanophores is distributed more evenly.

243 Validation of reference genes 
244 qPCR-based gene expression analyses depend on comparisons with stably expressed reference

245 genes (Kubista et al. 2006), which have to be validated for the species and the specific

246

247

248

249

250

251

252

253

254

255

256

257

258

259

260

261

262

263

264

265

266

267

268

269

270

271

272

273

experimental conditions in each study (Ahi et al. 2013). To this aim, we tested the expression of seven reference gene candidates on the cDNA generated from each of the 12 fin regions. The expression levels of the reference gene candidates varied from $a c t b 1$, with the highest expression (lowest Cq) (Fig. S1), to efla and hprtl with the lowest expressions (highest Cq). Next, the genes were ranked based on three algorithms, i.e. BestKeeper, geNorm and NormFinder, and standard deviation (SD) as described in (Ahi et al. 2013) (Table 2). Among the reference genes, tbp ranked first by geNorm and NormFiner and second by BestKeeper analyses (Table 2). Hence, the data indicated high expression stability of tbp and suggested it as a suitable normalization factor to accurately quantify differences in gene expression between the fin regions.

\section{Expression analyses of candidate genes}

To assist the cellular characterization of the fin patterns, we investigated the expression levels of an iridophore lineage specific marker ltk (Lopes et al. 2008) and of the melanosome marker slc24a5 (Lamason et al. 2005) in the individual fin regions. The expression level of ltk was significantly higher in the white-coloured regions of the dorsal and caudal fins (D-2 and Cd-2) than in the corresponding ventral regions (A-2 and $\mathrm{Cv}-2)$, confirming that iridophores are accumulated in the white stripes. In contrast, expression of $l t k$ in the distal and in the proximal fin regions was homogeneous across fins (Fig. 2E) (Table S3). The expression level of slc24a5 varied significantly among fins for each of the three fin region classes (Fig. 2E). Moreover, slc24a5 expression was significantly correlated with melanophore density across all fin regions $(\mathrm{r}=0.89, \mathrm{p}<0.0001)$, although the increase of slc24a5 expression levels with melanophore number was stronger in the dorsal $(\mathrm{D}, \mathrm{Cd})$ than in the ventral (A, Cv) fin tissues (Fig. S2). Variation in the association between melanophore numbers and slc24a5 expression levels was also observed among fin regions, as the correlation was significant in the distal and the middle regions $(\mathrm{r}=0.73$, $\mathrm{p}=0.001 ; \mathrm{r}=0.76, \mathrm{p}=0.0007$, respectively) but not in the proximal regions of the fins $(\mathrm{r}=0.22$, $\mathrm{p}=0.42$ ). This suggests that variation in melanosome densities within the melanophores may also contribute to fin color contrasts. 
274 Since the total number of melanophores, summed across regions, was constant in all fins, we

275 next determined the average expression levels of each of the candidate target genes across the

276 three regions of each fin and compared them among fins in order to identify spatial (particularly

277 dorso-ventral) differentiation in gene expression. The selected candidate genes are known to be

278 involved in stripe formation and/or adult pigmentation in zebrafish (see the details in Table 1).

279 One of the genes, kir7.1 (kcnj13), had very low expression levels $(\mathrm{Cq}>35)$ and therefore was

280 discarded from rest of the analysis. This, however, suggests that kir7.1 expression is not required

281 for chromatophores in fin regions of adult N. meeli, which is in agreement with findings in

282 zebrafish, where the function of kir7.1 was not necessary for pigment cell survival in adults

283 (Iwashita et al. 2006). Seven genes, igsf11, ltk, mitfa, mpv17, pmel, slc24a5 and slc45a2, showed

284 differential expression between the fins (Fig. 3A). The expression level of the melanosome

285 formation gene slc24a5 was significantly lower in the anal fin than in the other fins. Given that

286 melanophore counts did not differ across fins (Fig. 2D), this indicates a reduced melanosome

287 number in the melanophores of the anal fin. Furthermore, owing to the dorsal white stripes,

288 expression levels of the iridophore marker $l t k$ were significantly higher in the dorsal than in the

289 ventral fin tissues. Dorso-ventral differences were also observed in the expression levels of

290 igsf11, mitfa, pmel and slc45a2 (D, Cd > A, Cv), whereas mpv17 showed differential expression

291 along the posterior-anterior axis (D, A $>C d, C v)$.

292 Next, we were interested in those genes which showed overall dorso-ventral expression

293 differences across the fins, and compared their expression within the distal, middle and proximal

294 regions separately. Most interestingly, two genes, igsfl1 and pmel, displayed higher expression

295 in the black and in the white regions (D-1, Cd-1, and D-2, Cd-2) than in the corresponding

296 ventral regions (Fig. 3B) (Table S3). Importantly, the elevated expression of these genes in the

297 dark stripe was not simply due to the higher density of melanophores in these regions, as the

298 differences persisted after correcting for the number of melanophores (last row in Fig. 3B).

299 Elevated expression in both black and white stripes suggests that igsfl1 and pmel have similar

300 expression and potential function(s) in both iridophores and melanophores, which might emanate

301 from their shared neural crest cell origin (Curran et al. 2010).

302 In contrast, the elevated expression levels of two further genes, mitfa and slc45a2, in the black

303 stripe regions compared to the corresponding ventral regions (first row in Fig. 3B) levelled out

304 after correction for differences in melanophore density among fin regions (last row in Fig. 3B). 
305 As discussed before, ltk expression was elevated only in the white stripes (Fig. 2E), consistent 306 with its expression in iridophores.

307 Finally, we extended our study by predicting potential TF biding sites in the upstream promoter 308 sequences of igsfl1 and pmel in Nile tilapia, an African cichlid with high quality annotated 309 genome. Using different motif enrichment tools, we identified tens of motifs enriched in the 310 promoter sequences of both genes. After parsing the motifs against the known TF binding sites in vertebrates, we compiled lists of top potential TFs binding to each motif (Table S2). We then analysed the expression of six of the TFs, which were predicted by all of the three motif enrichment tools and implicated in pigmentation processes (Barrallo-Gimeno et al. 2004; Cook \& Sturm 2008; Li et al. 2009; Agarwal et al. 2011; Besch \& Berking 2014; Natarajan et al. 2014) (Fig. 4). Five of these TFs showed slight but significant expression differences between the fins (Fig. 4A), however only one TF, irfl, showed dorso-ventral differences (D, Cd < A, Cv). This pattern was confirmed in comparisons among anatomically equivalent regions, as the reduced expression of irfl in the black stripe regions (first row in Fig. 4B) was robust against the correction for melanophore density (last row in Fig. 4B).

We also tested for expression correlations among the seven differentially expressed target genes (identified in Fig. 3A) and the six predicted TFs (Fig. 4C). The results showed positive expression correlations (blue shadings in Fig. 4C) between several pairs of target genes, including igsfl1 and pmel, as well as negative expression correlations (red shadings) between target genes and three TFs, irfl, irf2 and ap2a. Notably, strong expression correlations with several target genes were observed for irf1, which was negatively correlated with igsf11, mitfa, pmel and slc45a2.

\section{Discussion}

329 Patterns of dark and light stripes are found in many fish species and may not only reflect spatial 330 variation in the number of chromatophores, but can also arise from differences in the 331 pigmentation of the individual chromatophores (Parichy 2006; Greenwood et al. 2012). In the 332 here investigated cichlid fish, Neolamprologus meeli, the dorso-ventrally distinct fin stripes 333 involved differences in the spatial distribution of a constant number of melanophores, i.e. their 334 aggregation and depletion in the dorsal black and white stripes, respectively, versus a more 
335 homogeneous melanophore density in the ventral fin regions. Although melanophore density in

336 the $N$. meeli fin samples showed the expected gradient between black, grey and white fin regions,

337 its correlation with the expression level of the melanosome marker slc24a5 was not consistent

338 across fin regions. Slc24a5 encodes an intracellular membrane cation exchanger predominantly

339 present in melanosomes. Its tissue expression level has been shown to be associated with the

340 number of melanin-producing cells, and reduced expression is associated with fewer, smaller and

341 less pigmented melanosomes (Lamason et al. 2005). The mechanism by which slc24a5

342 expression can be regulated differently across melanophore subpopulations in distinct body parts

343 is unclear but it might involve the nonsense-mediated mRNA decay pathway (Wittkopp et al.

344 2009). Our data suggest that the melanin-based colour differences among fin regions of N. meeli

345 are primarily due to differences in melanophore density, with additional variation contributed by

346 variation in melanophore pigmentation.

347 The light-reflecting iridophores are not individually discernible, and we used the expression of

348 the iridophore marker gene ltk to confirm their presence and trace their distribution in the fin

349 tissue. ltk encodes a member of tyrosine kinase receptors and its expression is essential for fate

350 specification of iridophores and formation of iridophore-containing stripes in adult zebrafish

351 (Lopes et al. 2008). Ltk expression was detected in all fin regions, but was significantly elevated

352 in the white stripes, which is consistent with an aggregation of iridophores in these regions. This

353 iridophore aggregation could also be involved in the development of the black stripe distal to the

354 white stripe. In the zebrafish dermis, iridophores repel melanophores on the short range but

355 support their aggregation at a longer distance, and thus contribute to melanophore stripe

356 formation (Frohnhöfer et al. 2013).

357 Since the stripe pattern of the $N$. meeli fins is dorsally restricted, we were primarily interested in

358 genes displaying a corresponding dorso-ventral difference in their expression levels. Two of the

359 investigated candidate genes, igsf11 and pmel, followed this pattern in comparisons among fins

360 as well as among analogous fin regions after correction for melanophore density. Expression

361 levels of both genes were higher in the dorsal black and white stripe regions than in the

362 corresponding ventral fin regions (Fig. 3B). Igsf11 encodes the immunoglobulin superfamily

363 member 11, a classical cell adhesion molecule, which mediates cell adhesion and promotes the

364 migration and survival of melanophores and their precursors during adult stripe formation in

365 zebrafish (Eom et al. 2012). Interestingly, mutations in igsf11 can have local effects. While a 
366 homozygous mutation in the fourth exon of igsfl1 induces severe irregularities in both body and

367 fin stripes of adult zebrafish, defects caused by mutations in the second exon are mainly

368

369

370

371

372

373

374

375

376

377

378

379

380

381

382

383

384

385

386

387

388

389

390

391

392

393

394

395

restricted to ventral body stripes but not apparent in fins (Eom et al. 2012). Since the melanophores of zebrafish igsfl1 mutants failed to migrate, the higher expression of igsfl1 in both black and white stripes of $N$. meeli might suggest an increased motility of melanophores in these regions. Furthermore, increased igsfl1 expression may also affect the arrangement of iridophores. Although the function of igsfl1 in iridophores is unclear, Tjpla, a tight junction protein recently identified as regulator of iridophore organization in zebrafish stripes, has been suggested to be an interacting partner of igsf11 protein in relevant cellular processes (Fadeev et al. 2015).

The other gene with dorsally elevated expression levels, pmel, encodes a melanosome protein (Silver), which plays an essential role in the structural organization of premelanosomes and the formation of intra-lumenal fibrils during melanosome biogenesis (Schonthaler et al. 2005). In homozygous zebrafish mutants of pmel, changes in the shape, positioning and melanin content of melanophores result in hypopigmented adults (Schonthaler et al. 2005). The function of pmel in the formation of pigment patterns has not been investigated, however, its differential expression was suggested as a contributing factor to the dark-light stripe formation in freshwater threespine sticklebacks compared to marine sticklebacks with evenly distributed melanophores and iridophores throughout skin (Greenwood et al. 2012).

The increased expression of igsf11 and pmel in both black and white regions of the fins might represent an overlapping transcriptional signature of melanophore and iridophore subpopulations emanating from shared developmental origins in the neural crest (Curran et al. 2010). In zebrafish, an attempt to find overlapping transcriptional signature between melanophores and iridophores identified 62 genes with similar expression patterns in both chromatophores, but igsfl1 and pmel were not among them (Higdon et al. 2013). However, the study was done using larval melanophores and iridophores from the body and not from the fins (Higdon et al. 2013). This could imply that the dorsally distinct stripe pattern in $N$. meeli fins involves a novel regulatory mechanism with locally restricted activity in the dorsal fin regions, which induces igsfl1 and pmel in both chromatophore classes and affects cell migration and melanosome biogenesis. 
396 We also found an overall positive expression correlation between igsfl1 and pmel across all fin 397 regions, suggesting a potential co-regulation through a shared upstream transcriptional regulator. 398 There is no evidence yet for such a mechanism in fish, but a recent computational study in human has predicted TFs, including Ap2a and Mitf, and small regulatory RNAs, such as mir-

400

401

402

403

404

405

406

407

408

409

410

411

412

413

414

415

416

417

418

419

420

421

422

423

424

425

426
221, as shared upstream regulators of igsfl1 and pmel in specific melanocyte lineages (Rambow et al. 2015). Here, we have already tested mitfa expression in our candidate gene survey and did not detect elevated expression in the dorsal black and white stripes. In addition, mitfa showed positive expression correlation with pmel but not with igsf11 (Fig. 4C). Among the shared TFs predicted by the motif enrichment approach employed in the present study, only irfl displayed dorso-ventrally distinct expression (with higher expression level in ventral regions) (Fig. 4A-B). Moreover, irfl showed negative expression correlations not only with igsfl1 and pmel but also with mitfa and slc45a2 across the fin regions (Fig. 4C). The gene encodes a member of the interferon regulatory transcription factor family and mediates a cytokine-dependent hypopigmentation process in human and mice melanocytes (Natarajan et al. 2014). The mechanism, by which Irfl impedes pigmentation, appears to be involved in melanosome maturation and is independent of Mitf regulation (Natarajan et al. 2014). The expression pattern of irfl in the $N$. meeli fins, the enrichment of its binding sites in igsfl1 and pmel promoter regions together with the regulatory role of both irfl and pmel in melanosome biogenesis suggest irfl as a strong candidate for the regulation of the observed fin colour phenotype. More specifically, irfl might act as suppressor of both igsf11 and pmel in the chromatophores.

Finally, we note that the involvement in dorso-ventrally distinct colour patterning of those genes, which did not show the expected expression in our study, should not be discarded based solely on mRNA expression data. For instance, our TF prediction also included $a p 2 a$, which encodes a TF essential for subsets of neural crest derivatives, including subpopulations of pigment cells. Its loss-of-function mutation in zebrafish leads to defects in the migration and differentiation of melanophores and iridophores, but not xanthophores (Knight et al. 2004; Li \& Cornell 2007). Interestingly, the zebrafish ap 2 a mutant exhibits a reduced number of iridophores and melanophores in ventral and lateral stripes but not in dorsal stripes (Knight et al. 2004). Similarly, locally restricted effects on stripe patterning are known for a structural mutation in igsf11 (Eom et al. 2012). Therefore, while our results mark pmel, igsf11 and irfl as likely components of the distinct dorso-ventral fin patterning in N. meeli, additional studies are needed 
427 to clarify the roles of other candidate genes. It is also important to investigate whether the same

428 genes are involved in stripe pattern formation during development, and particularly, at early

429 emergence of the pattern in fins.

430

431 Conclusions

432 Variation in colours and patterns contributes significantly to the tremendous phenotypic diversity

433 among fishes. Elucidating the molecular basis of this diversity is a stimulating challenge to

434 research in both model and non-model species, and promises significant insight in the

435 mechanisms that translate sexual and natural selection pressures into phenotypic variation. In our

436 work, we capitalized on a naturally occurring, dorsally restricted fin pattern phenotype to

437 investigate the mechanisms behind colour pattern differentiation in dorsal versus ventral regions.

438 The investigated fin colour pattern was associated with variation in melanophore and iridophore

439 densities, and corresponded with the gene expression patterns of two candidate target genes,

440 igsfl1 and pmel, and their predicted shared upstream regulator irfl. Further studies are required

441 to identify functional relationships between these genes and other potential components of this

442 process.

443

444 Acknowledgements

445 The authors thank Wolfgang Gessl for his responsible management of our fish facility and

446 photography of the fishes. We also thank Holger Zimmermann and Stephan Koblmüller for

447 sharing their precious knowledge on cichlid fishes of Lake Tanganyika, as well as Silke Werth

448 and the Institute of Plant Sciences at University of Graz for technical assistance.

\section{References}

451

452

453

454

455

456

457
Agarwal P., Verzi MP., Nguyen T., Hu J., Ehlers ML., McCulley DJ., Xu S-M., Dodou E., Anderson JP., Wei ML., Black BL. 2011. The MADS box transcription factor MEF2C regulates melanocyte development and is a direct transcriptional target and partner of SOX10. Development (Cambridge, England) 138:2555-65.

Ahi EP., Guðbrandsson J., Kapralova KH., Franzdóttir SR., Snorrason SS., Maier VH., Jónsson ZO. 2013. Validation of Reference Genes for Expression Studies during Craniofacial Development in Arctic Charr. PLoS ONE 8:e66389. 
458

459

460

461

462

463

464

465

466

467

468

469

470

471

472

473

474

475

476

477

478

479

480

481

482

483

484

485

486

487

488

489

490

491

492

Andersen CL., Jensen JL., Ørntoft TF. 2004. Normalization of real-time quantitative reverse transcription-PCR data: a model-based variance estimation approach to identify genes suited for normalization, applied to bladder and colon cancer data sets. Cancer research 64:5245-50.

Andersson LS., Wilbe M., Viluma A., Cothran G., Ekesten B., Ewart S., Lindgren G. 2013. Equine Multiple Congenital Ocular Anomalies and Silver Coat Colour Result from the Pleiotropic Effects of Mutant PMEL. PLoS ONE 8:e75639.

Bailey TL., Boden M., Buske FA., Frith M., Grant CE., Clementi L., Ren J., Li WW., Noble WS. 2009. MEME SUITE: tools for motif discovery and searching. Nucleic acids research 37:W202-8.

Barrallo-Gimeno A., Holzschuh J., Driever W., Knapik EW. 2004. Neural crest survival and differentiation in zebrafish depends on mont blanc/tfap2a gene function. Development (Cambridge, England) 131:1463-77.

Baxter LL., Hou L., Loftus SK., Pavan WJ. 2004. Spotlight on Spotted Mice: A Review of White Spotting Mouse Mutants and Associated Human Pigmentation Disorders. Pigment Cell Research 17:215-224.

Besch R., Berking C. 2014. POU transcription factors in melanocytes and melanoma. European Journal of Cell Biology 93:55-60.

Braasch I., Brunet F., Volff J-N., Schartl M. 2009. Pigmentation pathway evolution after wholegenome duplication in fish. Genome biology and evolution 1:479-93.

Braasch I., Volff J-N., Schartl M. 2008. The evolution of teleost pigmentation and the fishspecific genome duplication. Journal of Fish Biology 73:1891-1918.

Brawand D., Wagner CE., Li YI., Malinsky M., Keller I., Fan S., Simakov O., Ng AY., Lim ZW., Bezault E., Turner-Maier J., Johnson J., Alcazar R., Noh HJ., Russell P., Aken B., Alföldi J., Amemiya C., Azzouzi N., Baroiller J-F., Barloy-Hubler F., Berlin A., Bloomquist R., Carleton KL., Conte MA., D’Cotta H., Eshel O., Gaffney L., Galibert F., Gante HF., Gnerre S., Greuter L., Guyon R., Haddad NS., Haerty W., Harris RM., Hofmann HA., Hourlier T., Hulata G., Jaffe DB., Lara M., Lee AP., MacCallum I., Mwaiko S., Nikaido M., Nishihara H., Ozouf-Costaz C., Penman DJ., Przybylski D., Rakotomanga M., Renn SCP., Ribeiro FJ., Ron M., Salzburger W., Sanchez-Pulido L., Santos ME., Searle S., Sharpe T., Swofford R., Tan FJ., Williams L., Young S., Yin S., Okada N., Kocher TD., Miska EA., Lander ES., Venkatesh B., Fernald RD., Meyer A., Ponting CP., Streelman JT., Lindblad-Toh K., Seehausen O., Di Palma F. 2014. The genomic substrate for adaptive radiation in African cichlid fish. Nature 513:375-81.

Bronner ME., LeDouarin NM. 2012. Development and evolution of the neural crest: An 
493

494

495

496

497

498

499

500

501

502

503

504

505

506

507

508

509

510

511

512

513

514

515

516

517

518

519

520

521

522

523

524

525

526

527

overview. Developmental Biology 366:2-9.

Carlson JM., Chakravarty A., DeZiel CE., Gross RH. 2007. SCOPE: a web server for practical de novo motif discovery. Nucleic acids research 35:W259-64.

Cook AL., Sturm RA. 2008. POU domain transcription factors: BRN2 as a regulator of melanocytic growth and tumourigenesis. Pigment cell \& melanoma research 21:611-26.

Curran K., Lister JA., Kunkel GR., Prendergast A., Parichy DM., Raible DW. 2010. Interplay between Foxd3 and Mitf regulates cell fate plasticity in the zebrafish neural crest. Developmental Biology 344:107-118.

Eom DS., Inoue S., Patterson LB., Gordon TN., Slingwine R., Kondo S., Watanabe M., Parichy DM. 2012. Melanophore migration and survival during zebrafish adult pigment stripe development require the immunoglobulin superfamily adhesion molecule Igsf11. PLoS genetics 8:e1002899.

Fadeev A., Krauss J., Frohnhöfer HG., Irion U., Nüsslein-Volhard C. 2015. Tight Junction Protein 1a regulates pigment cell organisation during zebrafish colour patterning. eLife 4 .

Fernandes JMO., Mommens M., Hagen Ø., Babiak I., Solberg C. 2008. Selection of suitable reference genes for real-time PCR studies of Atlantic halibut development. Comparative Biochemistry and Physiology Part B: Biochemistry and Molecular Biology 150:23-32.

Flicek P., Ahmed I., Amode MR., Barrell D., Beal K., Brent S., Carvalho-Silva D., Clapham P., Coates G., Fairley S., Fitzgerald S., Gil L., García-Girón C., Gordon L., Hourlier T., Hunt S., Juettemann T., Kähäri AK., Keenan S., Komorowska M., Kulesha E., Longden I., Maurel T., McLaren WM., Muffato M., Nag R., Overduin B., Pignatelli M., Pritchard B., Pritchard E., Riat HS., Ritchie GRS., Ruffier M., Schuster M., Sheppard D., Sobral D., Taylor K., Thormann A., Trevanion S., White S., Wilder SP., Aken BL., Birney E., Cunningham F., Dunham I., Harrow J., Herrero J., Hubbard TJP., Johnson N., Kinsella R., Parker A., Spudich G., Yates A., Zadissa A., Searle SMJ. 2013. Ensembl 2013. Nucleic acids research 41:D48-55.

Frohnhöfer HG., Krauss J., Maischein H-M., Nüsslein-Volhard C. 2013. Iridophores and their interactions with other chromatophores are required for stripe formation in zebrafish. Development (Cambridge, England) 140:2997-3007.

Fujii R. 2000. The regulation of motile activity in fish chromatophores. Pigment cell research / sponsored by the European Society for Pigment Cell Research and the International Pigment Cell Society 13:300-19.

Greenwood AK., Cech JN., Peichel CL. 2012. Molecular and developmental contributions to divergent pigment patterns in marine and freshwater sticklebacks. Evolution \& development 14:351-62. 
528 Hauswirth R., Haase B., Blatter M., Brooks SA., Burger D., Drögemüller C., Gerber V., Henke 529 D., Janda J., Jude R., Magdesian KG., Matthews JM., Poncet P-A., Svansson V., Tozaki T., 530 Wilkinson-White L., Penedo MCT., Rieder S., Leeb T. 2012. Mutations in MITF and PAX3

531

532

533

534

535

536

537

538

539

540

541

542

543

544

545

546

547

548

549

550

551

552

553

554

555

556

557

558

559

560

561

562

Cause "Splashed White" and Other White Spotting Phenotypes in Horses. PLoS Genetics 8:e1002653.

Hellemans J., Mortier G., De Paepe A., Speleman F., Vandesompele J. 2007. qBase relative quantification framework and software for management and automated analysis of real-time quantitative PCR data. Genome biology 8:R19.

Higdon CW., Mitra RD., Johnson SL. 2013. Gene Expression Analysis of Zebrafish Melanocytes, Iridophores, and Retinal Pigmented Epithelium Reveals Indicators of Biological Function and Developmental Origin. PLoS ONE 8:e67801.

Hoekstra HE. 2006. Genetics, development and evolution of adaptive pigmentation in vertebrates. Heredity 97:222-234.

Iwashita M., Watanabe M., Ishii M., Chen T., Johnson SL., Kurachi Y., Okada N., Kondo S. 2006. Pigment Pattern in jaguar/obelix Zebrafish Is Caused by a Kir7.1 Mutation: Implications for the Regulation of Melanosome Movement. PLoS Genetics 2:e197.

Kelsh RN. 2004. Genetics and Evolution of Pigment Patterns in Fish. Pigment Cell Research 17:326-336.

Kelsh RN., Harris ML., Colanesi S., Erickson CA. 2009. Stripes and belly-spots -- a review of pigment cell morphogenesis in vertebrates. Seminars in cell \& developmental biology 20:90-104.

Kinoshita K., Akiyama T., Mizutani M., Shinomiya A., Ishikawa A., Younis HH., Tsudzuki M., Namikawa T., Matsuda Y. 2014. Endothelin Receptor B2 (EDNRB2) Is Responsible for the Tyrosinase-Independent Recessive White (mow) and Mottled (mo) Plumage Phenotypes in the Chicken. PLoS ONE 9:e86361.

Knight RD., Javidan Y., Nelson S., Zhang T., Schilling T. 2004. Skeletal and pigment cell defects in thelockjaw mutant reveal multiple roles for zebrafishtfap2a in neural crest development. Developmental Dynamics 229:87-98.

Kubista M., Andrade JM., Bengtsson M., Forootan A., Jonák J., Lind K., Sindelka R., Sjöback R., Sjögreen B., Strömbom L., Ståhlberg A., Zoric N. 2006. The real-time polymerase chain reaction. Molecular aspects of medicine 27:95-125.

Lamason RL., Mohideen M-APK., Mest JR., Wong AC., Norton HL., Aros MC., Jurynec MJ., Mao X., Humphreville VR., Humbert JE., Sinha S., Moore JL., Jagadeeswaran P., Zhao W., Ning G., Makalowska I., McKeigue PM., O’donnell D., Kittles R., Parra EJ., Mangini NJ., Grunwald DJ., Shriver MD., Canfield VA., Cheng KC. 2005. SLC24A5, a putative cation 
563

564

565

566

567

568

569

570

571

572

573

574

575

576

577

578

579

580

581

582

583

584

585

586

587

588

589

590

591

592

593

594

595

596

exchanger, affects pigmentation in zebrafish and humans. Science (New York, N.Y.) 310:1782-6.

Leclercq E., Taylor JF., Migaud H. 2009. Morphological skin colour changes in teleosts. Fish and Fisheries 11:159-193.

Li R., Maminishkis A., Banzon T., Wan Q., Jalickee S., Chen S., Miller SS. 2009. IFN $\gamma$ regulates retinal pigment epithelial fluid transport. American journal of physiology. Cell physiology 297:C1452-65.

Li L., Li D., Liu L., Li S., Feng Y., Peng X., Gong Y. 2015. Endothelin Receptor B2 (EDNRB2) Gene Is Associated with Spot Plumage Pattern in Domestic Ducks (Anas platyrhynchos). PLOS ONE 10:e0125883.

Li W., Cornell RA. 2007. Redundant activities of Tfap2a and Tfap2c are required for neural crest induction and development of other non-neural ectoderm derivatives in zebrafish embryos. Developmental Biology 304:338-354.

Lister JA., Close J., Raible DW. 2001. Duplicate mitf Genes in Zebrafish: Complementary Expression and Conservation of Melanogenic Potential. Developmental Biology 237:333344.

Lopes SS., Yang X., Müller J., Carney TJ., McAdow AR., Rauch G-J., Jacoby AS., Hurst LD., Delfino-Machín M., Haffter P., Geisler R., Johnson SL., Ward A., Kelsh RN. 2008. Leukocyte Tyrosine Kinase Functions in Pigment Cell Development. PLoS Genetics 4:e1000026.

Luehr S., Hartmann H., Söding J. 2012. The XXmotif web server for eXhaustive, weight matriXbased motif discovery in nucleotide sequences. Nucleic acids research 40:W104-9.

Lynn Lamoreux M., Kelsh RN., Wakamatsu Y., Ozato K. 2005. Pigment pattern formation in the medaka embryo. Pigment Cell Research 18:64-73.

Maan ME., Sefc KM. 2013. Colour variation in cichlid fish: Developmental mechanisms, selective pressures and evolutionary consequences. Seminars in Cell \& Developmental Biology 24:516-528.

Mahony S., Benos P V. 2007. STAMP: a web tool for exploring DNA-binding motif similarities. Nucleic acids research 35:W253-8.

Matsushima Y., Shinkai Y., Kobayashi Y., Sakamoto M., Kunieda T., Tachibana M. 2002. A mouse model of Waardenburg syndrome type 4 with a new spontaneous mutation of the endothelin-B receptor gene. Mammalian genome : official journal of the International Mammalian Genome Society 13:30-5.

Matys V., Fricke E., Geffers R., Gössling E., Haubrock M., Hehl R., Hornischer K., Karas D., 
597

598

599

600

601

602

603

604

605

606

607

608

609

610

611

612

613

614

615

616

617

618

619

620

621

622

623

624

625

626

627

628

629

630

Kel AE., Kel-Margoulis O V., Kloos D-U., Land S., Lewicki-Potapov B., Michael H., Münch R., Reuter I., Rotert S., Saxel H., Scheer M., Thiele S., Wingender E. 2003. TRANSFAC: transcriptional regulation, from patterns to profiles. Nucleic acids research 31:374-8.

Metallinos DL., Bowling AT., Rine J. 1998. A missense mutation in the endothelin-B receptor gene is associated with Lethal White Foal Syndrome: an equine version of Hirschsprung disease. Mammalian genome : official journal of the International Mammalian Genome Society 9:426-31.

Mills MG., Patterson LB. 2009. Not just black and white: Pigment pattern development and evolution in vertebrates. Seminars in Cell \& Developmental Biology 20:72-81.

Miwa M., Inoue-Murayama M., Aoki H., Kunisada T., Hiragaki T., Mizutani M., Ito S. 2007. Endothelin receptor B2 (EDNRB2) is associated with the panda plumage colour mutation in Japanese quail. Animal Genetics 38:103-108.

Natarajan VT., Ganju P., Singh A., Vijayan V., Kirty K., Yadav S., Puntambekar S., Bajaj S., Dani PP., Kar HK., Gadgil CJ., Natarajan K., Rani R., Gokhale RS. 2014. IFN- $\gamma$ signaling maintains skin pigmentation homeostasis through regulation of melanosome maturation. Proceedings of the National Academy of Sciences 111:2301-2306.

Olsvik PA., Søfteland L., Lie KK. 2008. Selection of reference genes for qRT-PCR examination of wild populations of Atlantic cod Gadus morhua. BMC Research Notes 1:47.

Parichy DM. 2006. Evolution of danio pigment pattern development. Heredity 97:200-210.

Pashay Ahi E., Walker BS., Lassiter CS., Jónsson ZO. 2016. Investigation of the effects of estrogen on skeletal gene expression during zebrafish larval head development. PeerJ 4:e1878.

Pfaffl MW. 2001. A new mathematical model for relative quantification in real-time RT-PCR. Nucleic acids research 29:e45.

Pfaffl MW., Tichopad A., Prgomet C., Neuvians TP. 2004. Determination of stable housekeeping genes, differentially regulated target genes and sample integrity: BestKeeper-Excel-based tool using pair-wise correlations. Biotechnology letters 26:509-15.

Ramakers C., Ruijter JM., Deprez RHL., Moorman AF. 2003. Assumption-free analysis of quantitative real-time polymerase chain reaction (PCR) data. Neuroscience letters 339:62-6.

Rambow F., Job B., Petit V., Gesbert F., Delmas V., Seberg H., Meurice G., Van Otterloo E., Dessen P., Robert C., Gautheret D., Cornell RA., Sarasin A., Larue L. 2015. New Functional Signatures for Understanding Melanoma Biology from Tumor Cell LineageSpecific Analysis. Cell Reports 13:840-853. 
632

633

634

635

636

637

638

639

640

641

642

643

644

645

646

647

648

649

650

651

652

653

654

655
631 Schonthaler HB., Lampert JM., von Lintig J., Schwarz H., Geisler R., Neuhauss SCF. 2005. A mutation in the silver gene leads to defects in melanosome biogenesis and alterations in the visual system in the zebrafish mutant fading vision. Developmental Biology 284:421-436.

Singh AP., Nüsslein-Volhard C. 2015. Zebrafish Stripes as a Model for Vertebrate Colour Pattern Formation. Current Biology 25:R81-R92.

Small BC., Murdock CA., Bilodeau-Bourgeois AL., Peterson BC., Waldbieser GC. 2008. Stability of reference genes for real-time PCR analyses in channel catfish (Ictalurus punctatus) tissues under varying physiological conditions. Comparative Biochemistry and Physiology Part B: Biochemistry and Molecular Biology 151:296-304.

Tang R., Dodd A., Lai D., McNabb WC., Love DR. 2007. Validation of zebrafish (Danio rerio) reference genes for quantitative real-time RT-PCR normalization. Acta biochimica et biophysica Sinica 39:384-90.

Vandesompele J., De Preter K., Pattyn F., Poppe B., Van Roy N., De Paepe A., Speleman F. 2002. Accurate normalization of real-time quantitative RT-PCR data by geometric averaging of multiple internal control genes. Genome biology 3:RESEARCH0034.

Wittkopp N., Huntzinger E., Weiler C., Sauliere J., Schmidt S., Sonawane M., Izaurralde E. 2009. Nonsense-Mediated mRNA Decay Effectors Are Essential for Zebrafish Embryonic Development and Survival. Molecular and Cellular Biology 29:3517-3528.

Yang CG., Wang XL., Tian J., Liu W., Wu F., Jiang M., Wen H. 2013. Evaluation of reference genes for quantitative real-time RT-PCR analysis of gene expression in Nile tilapia (Oreochromis niloticus). Gene 527:183-192.

Zheng W., Sun L. 2011. Evaluation of housekeeping genes as references for quantitative real time RT-PCR analysis of gene expression in Japanese flounder (Paralichthys olivaceus). Fish \& Shellfish Immunology 30:638-645. 


\section{Figure 1}

Dorsally restricted melanin pigmentation patterns in different vertebrate species.

(A) On top, adult male and female Lake Tanganyika cichlid fish, Neolamprologus meeli, and below, a schematic drawing displays sharp black-white stripes in the edges of the dorsal fin (D) and the dorsal half of the caudal fin (Cd), whereas the white stripe is missing and the black stripe is replaced by less sharp dark grey stripe in the anal fin (A) and the ventral half of caudal fin (Cv). The blue dashed squares delineate the fin tissue analysed in the present study; the numbers 1-3 in the red circles distinguish the investigated fin regions based on their coloration and distal to proximal location. (B) Loss-of-function mutations in Mitf and Ednrb genes cause skin phenotypes with dorsally restricted black pigmentation in horse and mice. A converse colour phenotype has been observed in black Silver coloured horses as a result of a mutation in the PMEL gene (only mane and tail are white). (C) Loss-of-function mutations in an avian paralog of the Ednrb1 gene, EDNRB2, cause phenotypes with blackwhite plumage (dorsal black spots) in Japanese quail, domestic chicken and duck. 
A
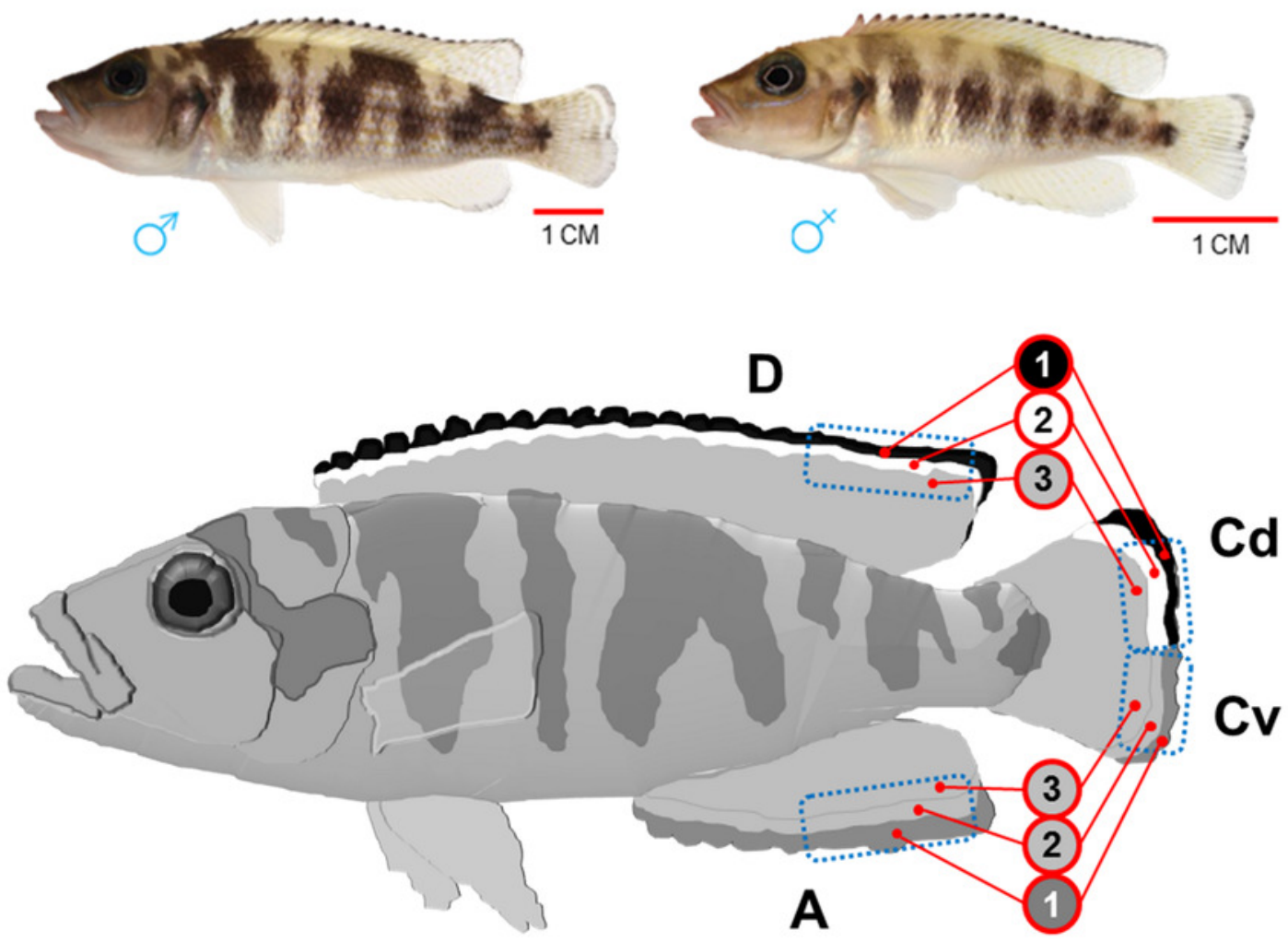

B

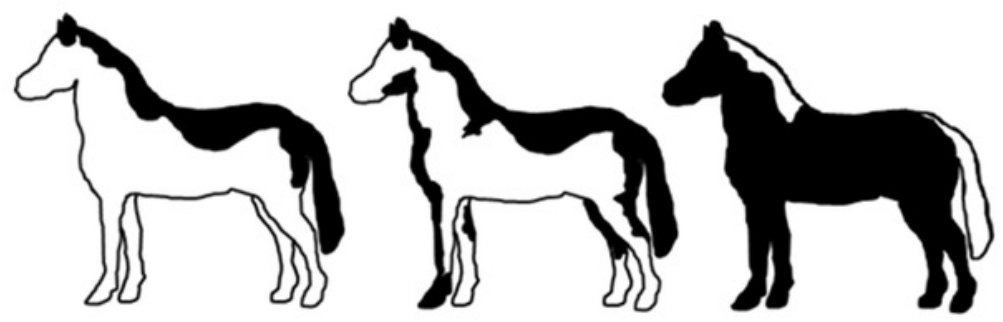

Splashed White horse Gene: MITF
Frame Overo horse Gene: EDNRB
Black Silver coloured horse Gene: PMEL

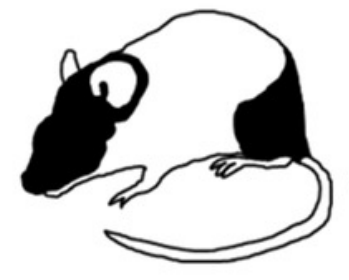

Piebald mice Gene: Ednrb

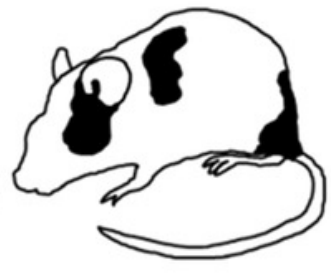

Black and White spotted mice Gene: Mitf

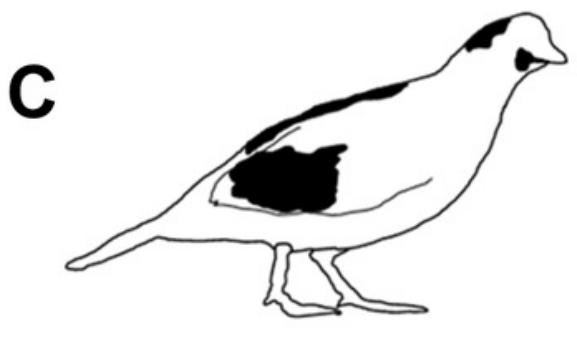

Panda plumage Japanese quail

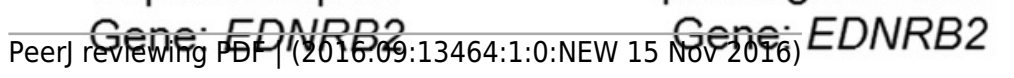

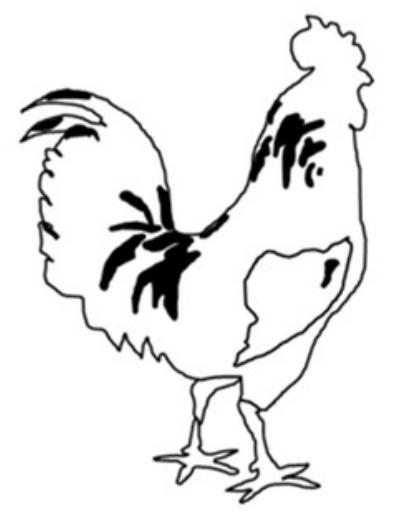

Mottled and White plumage chicken 


\section{Table $\mathbf{1}$ (on next page)}

Selected candidate target genes and available literature indicating their role in pigmentation and stripe formation in zebrafish. 


\begin{tabular}{|c|c|c|c|c|c|c|}
\hline \multirow{2}{*}{ Gene } & \multicolumn{3}{|c|}{ Developmental formation } & \multirow{2}{*}{$\begin{array}{c}\text { Adult } \\
\text { pigmentation* }\end{array}$} & \multirow{2}{*}{$\begin{array}{c}\text { Stripe } \\
\text { formation }\end{array}$} & \multirow{2}{*}{ References } \\
\hline & Melanophore & Iridophore & Xanthophore & & & \\
\hline$b n c 2$ & + & + & + & + & + & (Lang et al. 2009) \\
\hline $\operatorname{csflr}$ & + & $?$ & + & + & + & $\begin{array}{c}\text { (Parichy \& Turner } \\
2003 \text { ) }\end{array}$ \\
\hline ece2 & $?$ & + & $?$ & + & + & $\begin{array}{c}\text { (Krauss et al. } \\
\text { 2014) }\end{array}$ \\
\hline ednrb1 & + & + & $?$ & + & + & $\begin{array}{c}\text { (Parichy et al. } \\
\text { 2000) }\end{array}$ \\
\hline$f b x w 4$ & + & + & $?$ & + & + & $\begin{array}{c}\text { (Kawakami et al. } \\
2000)\end{array}$ \\
\hline igsf11 & + & $?$ & $?$ & + & + & (Eom et al. 2012) \\
\hline kita & + & $?$ & $?$ & + & + & $\begin{array}{c}\text { (Parichy et al. } \\
\text { 1999)(Mills et al. } \\
\text { 2007)(Dooley, } \\
\text { Mongera, et al. } \\
\text { 2013) }\end{array}$ \\
\hline kir7.1 & + & - & + & - & + & $\begin{array}{c}\text { (Iwashita et al. } \\
\text { 2006) }\end{array}$ \\
\hline$l t k$ & $?$ & + & - & + & + & $\begin{array}{c}\text { (Fadeev et al. } \\
\text { 2016)(Lopes et al. } \\
\text { 2008) }\end{array}$ \\
\hline mitfa & + & $?$ & - & + & + & $\begin{array}{c}\text { (Lister et al. } \\
\text { 1999)(Johnson } \text { et } \\
\text { al. 2011) } \\
\end{array}$ \\
\hline$m p v 17$ & $?$ & + & $?$ & + & + & $\begin{array}{c}\text { (Krauss et al. } \\
\text { 2013) }\end{array}$ \\
\hline pmel & + & $?$ & $?$ & + & $?$ & $\begin{array}{c}\text { (Schonthaler et al. } \\
\text { 2005) }\end{array}$ \\
\hline slc $24 a 5$ & + & $?$ & $?$ & + & - & $\begin{array}{l}\text { (Lamason et al. } \\
\text { 2005) }\end{array}$ \\
\hline slc $45 a 2$ & $?$ & $?$ & $?$ & + & $?$ & $\begin{array}{l}\text { (Dooley, Schwarz, } \\
\text { et al. 2013) }\end{array}$ \\
\hline $\operatorname{sox} 10$ & + & $?$ & $?$ & $?$ & + & $\begin{array}{c}\text { (Dutton et al. } \\
\text { 2001)(Elworthy et } \\
\text { al. 2003) }\end{array}$ \\
\hline
\end{tabular}

* A role in adult pigmentation mainly indicates the requirement of gene function for survival of different chromatophore lineages or/and pigment formation in adult zebrafish

1 


\section{Figure 2}

Distribution of melanophores and expression of two chromatophore marker genes in fins of $N$. meeli.

Fins coded as in Fig. 1A. (A) Photographs of the fins of N. meeli taken on white and black background. Insets (red squares) in the caudal fin delineate the magnified area shown in B.

(B) The magnification of the caudal fin shows the sequence of black, white and grey coloration in the dorsal part of the fin (fin regions $C d-1, C d-2, C d-3$, respectively), whereas colour contrasts are lower in the ventral part of the fin (fin regions Cv-1, Cv-2 and Cv-3, respectively). Analogous patterns were found in the dorsal and anal fins. The chromatophore distribution in the dorsal and ventral parts of the caudal fin is depicted in the schematic drawings of two inter-ray regions (white and black dots represent iridophores and melanophores, respectively). (C) Melanophore densities in the distinct fin regions, grouped by anatomical equivalence into the distal fin regions ( $D-1, C d-1, C v-1$ and $A-1$ ), the middle fin regions ( $D-2, C d-2, C v-2$ and $A-2$ ) and the proximal fin regions (D-3, Cd-3, Cv-3 and A-3). Pairwise differences between individual fin regions are indicated by the letter codes of fin regions with significantly lower melanophore density $(P<0.01)$ above bars. (D) Melanophore density summed across fin regions in the $\mathrm{D}, \mathrm{Cd}, \mathrm{Cv}$ and $\mathrm{A}$ fins. There were no significant differences between fins. (E) The expression levels of Itk and s/c24a5 in the individual fin regions. Statistical comparisons were conducted among anatomically comparable regions, and pairwise differences between fin regions are indicated by the letter codes of fin regions with significantly lower expression $(P<0.01)$ above bars. In $\mathbf{C}-\mathbf{E}$, error bars represent standard deviations calculated from four biological replicates and the comparisons between groups were done by using Tukey-HSD. 
A

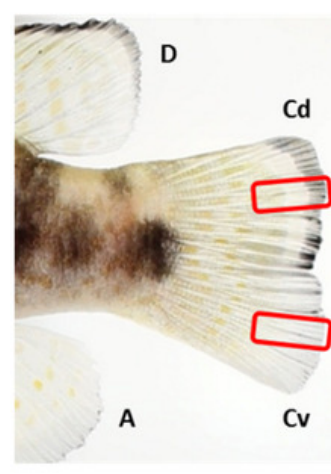

C

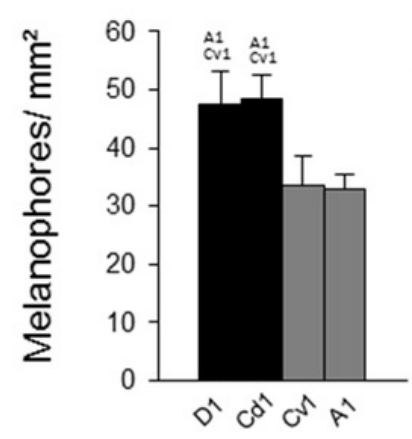

Distal fin

E

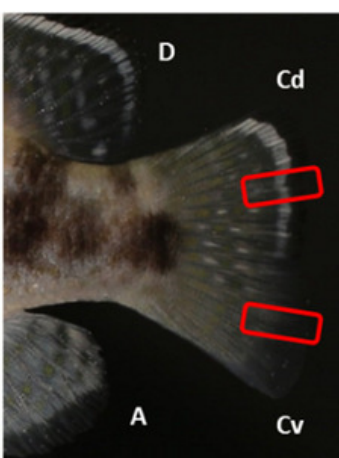

B

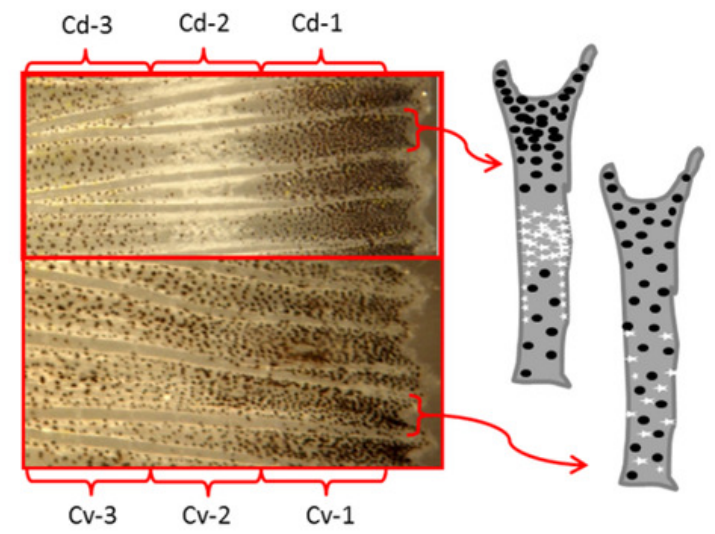

D

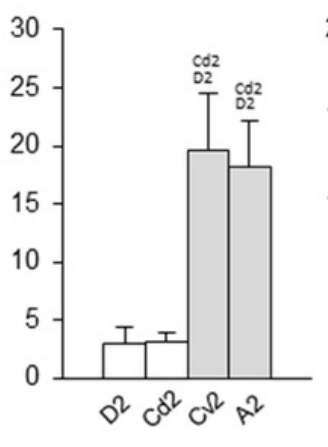

Middle fin

regions

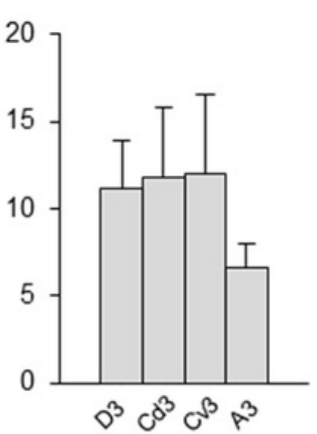

Proximal fin regions

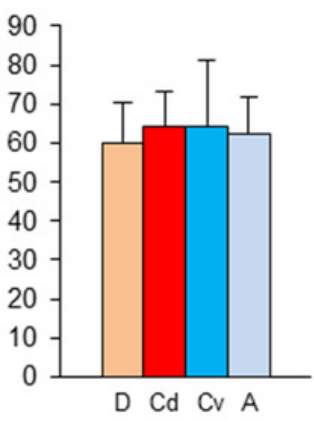

Across fins
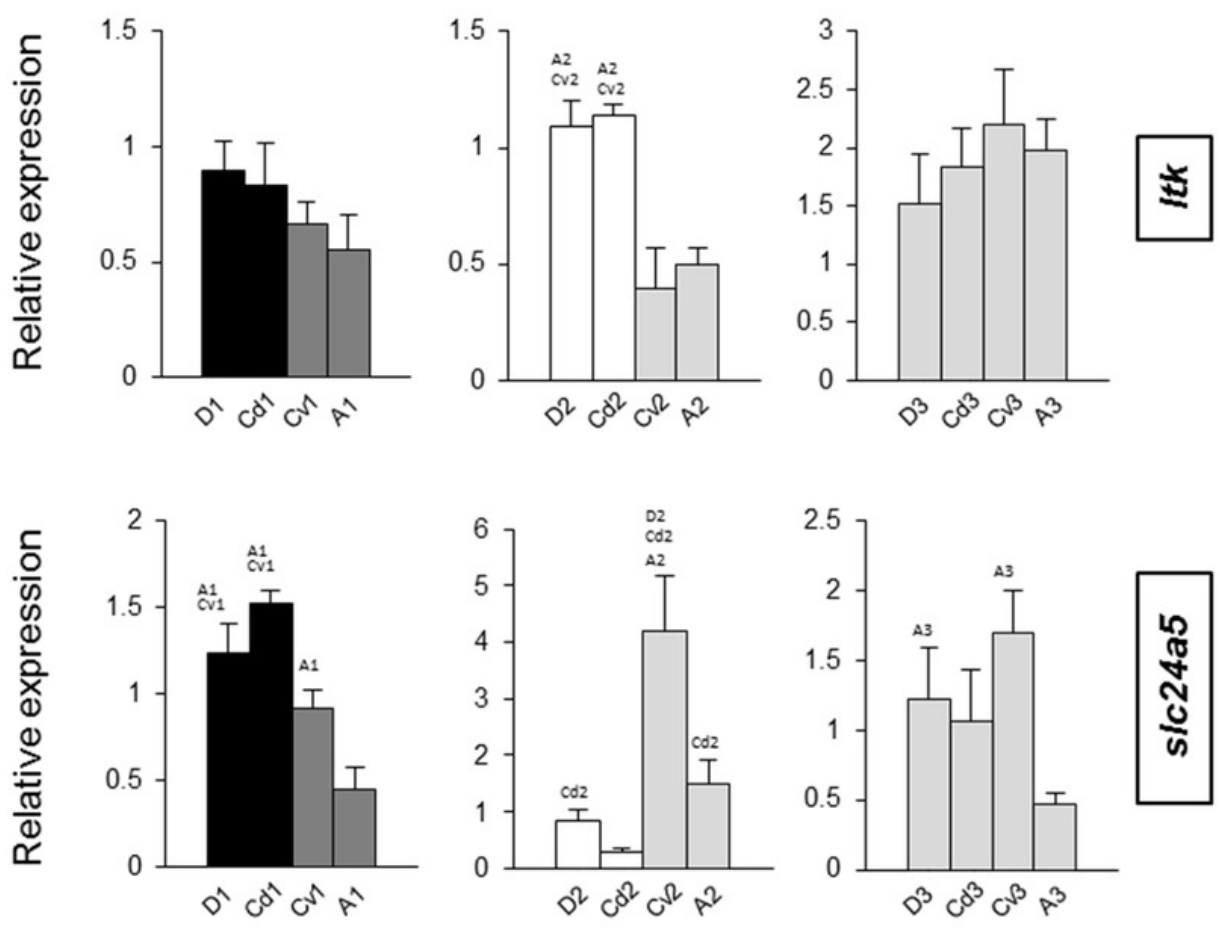

Distal fin

Middle fin

Proximal fin regions 


\section{Table 2 (on next page)}

Ranking and statistical analyses of candidate reference genes using BestKeeper, geNorm and NormFinder. 


\begin{tabular}{|c|c|c|c|c|c|c|c|}
\hline \multicolumn{4}{|c|}{ BestKeeper } & \multicolumn{2}{|c|}{ geNorm } & \multicolumn{2}{|c|}{ NormFinder } \\
\hline Ranking & $\mathbf{r}$ & Ranking & SD & Ranking & $\mathbf{M}$ & Ranking & SV \\
\hline rps18 & 0.992 & $a c t b 1$ & 1.027 & $t b p$ & 1.006 & $t b p$ & 0.069 \\
\hline$t b p$ & 0.987 & $t b p$ & 1.099 & rps18 & 1.023 & rps18 & 0.113 \\
\hline $\operatorname{rps} 11$ & 0.983 & efla & 1.160 & rps 11 & 1.030 & $a c t b 1$ & 0.141 \\
\hline$a c t b 1$ & 0.983 & rps11 & 1.217 & $a c t b 1$ & 1.035 & rps11 & 0.190 \\
\hline efla & 0.777 & rps 18 & 1.297 & efla & 1.470 & efla & 0.622 \\
\hline hprt1 & 0.718 & gapdh & 1.761 & hprt1 & 2.285 & hprt1 & 1.191 \\
\hline gapdh & 0.493 & hprt1 & 2.386 & gapdh & 2.352 & gapdh & 1.252 \\
\hline
\end{tabular}

1

2 Abbreviations: $\mathrm{SD}=$ Standard deviation, $\mathrm{r}=$ Pearson product-moment correlation coefficient, $\mathrm{SV}$

3 = stability value, $\mathrm{M}=\mathrm{M}$ value of stability. 


\section{Figure 3}

Expression differences of target genes among fin samples of $N$. meeli.

Fins and fin regions coded as in Fig. 1A. (A) The overall expression levels per fin, averaged across fin regions, of fourteen candidate target genes. (B) The expression levels of five selected genes, igsf11, mitfa, mpv17, pmel and s/c45a2, compared among anatomically equivalent fin regions. The last row represents expression levels in the distal fin regions corrected for melanophore numbers. Pairwise differences between fin regions are indicated by the letter codes of fin regions with significantly lower expression $(P<0.01)$ above bars. Error bars represent standard deviations calculated from four biological replicates and the comparisons between groups were done by using Tukey-HSD. 
A

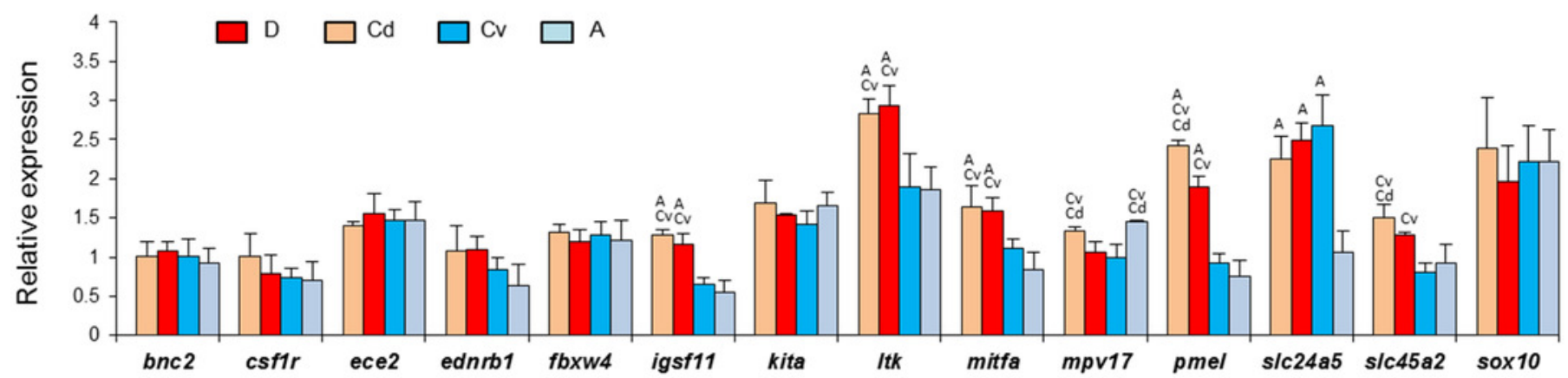

B

igsf11
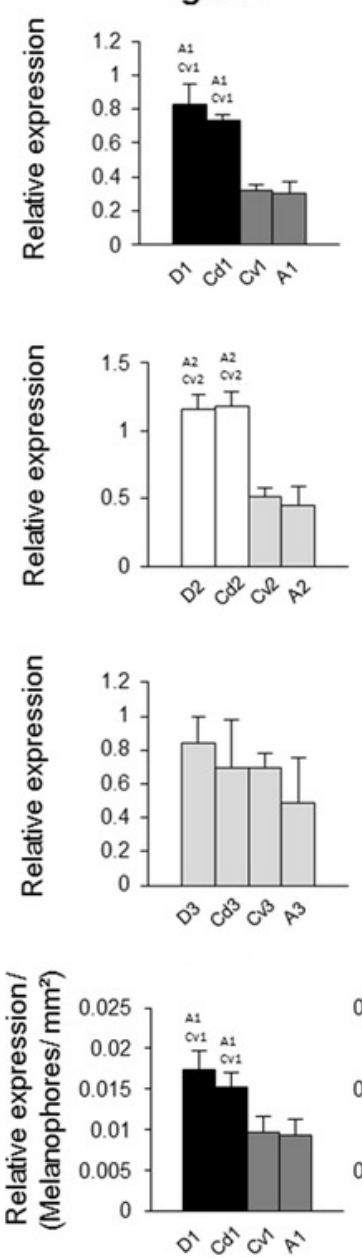

Fin regions mitfa
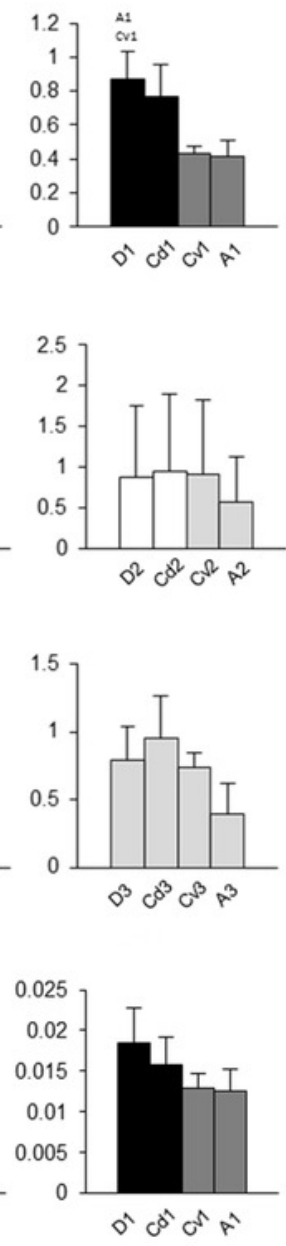

Fin regions mpv17

pmel
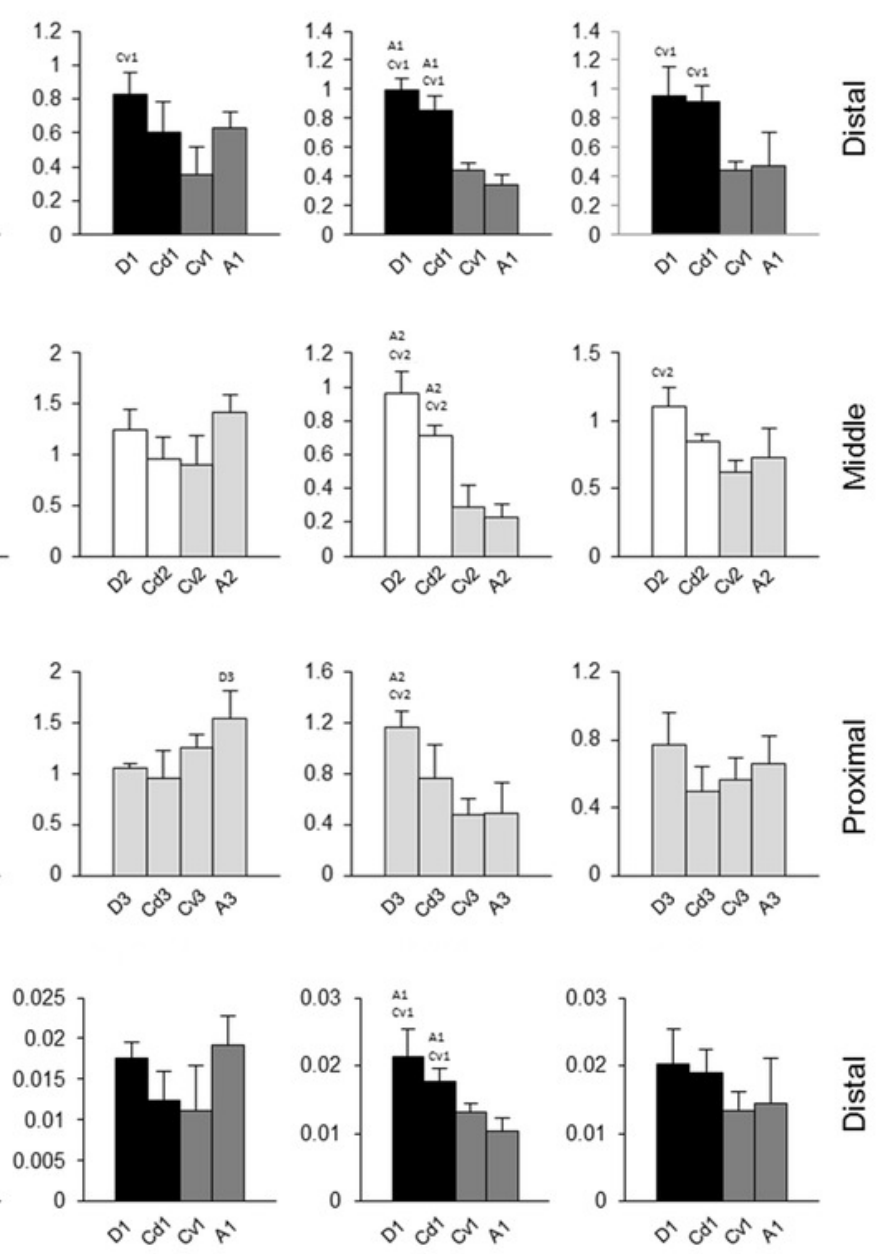

Fin regions
Fin regions

Fin regions 


\section{Figure 4}

Expression differences and expression correlations of predicted transcription factors in fin samples of $N$. meeli.

Fins and fin regions coded as in Fig. 1A. (A) The overall expression levels per fin, averaged across fin regions, of six transcription factors. (B) The expression levels of five selected transcription factors, ap2a, irf1, irf2, mef2c and pou3f2, compared among anatomically equivalent fin regions. The last row represents expression levels in the distal fin regions corrected for the melanophore numbers. Pairwise differences between fin regions are indicated by the letter codes of fin regions with significantly lower expression $(P<0.01)$ above bars. Error bars represent standard deviations calculated from four biological replicates and the comparisons between groups were done by using Tukey-HSD. (C) Significant expression correlations between seven target genes and five transcription factors examined in this study. Pearson correlation coefficients $(r)$ were calculated to assess pairwise expression similarities between genes. Blue and red shadings mark positive and negative expression correlation coefficients, respectively, which were significant with $\mathrm{P}<0.01(\mathrm{df}=$ 11) in 2-tailed tests. 

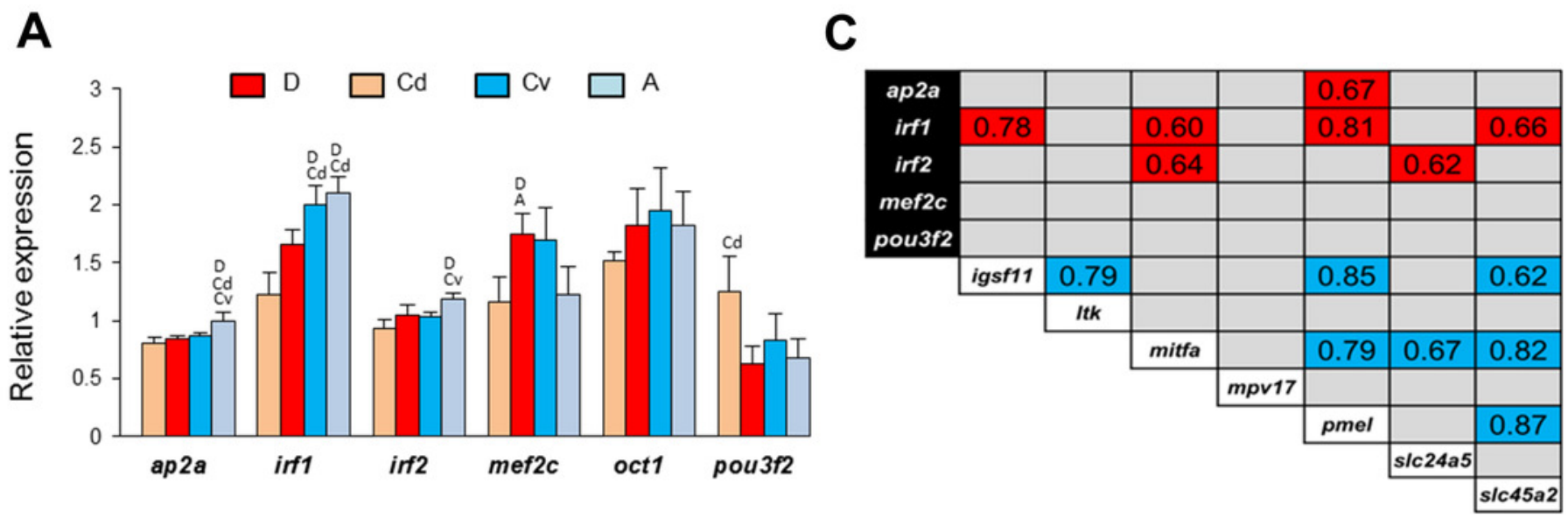

B
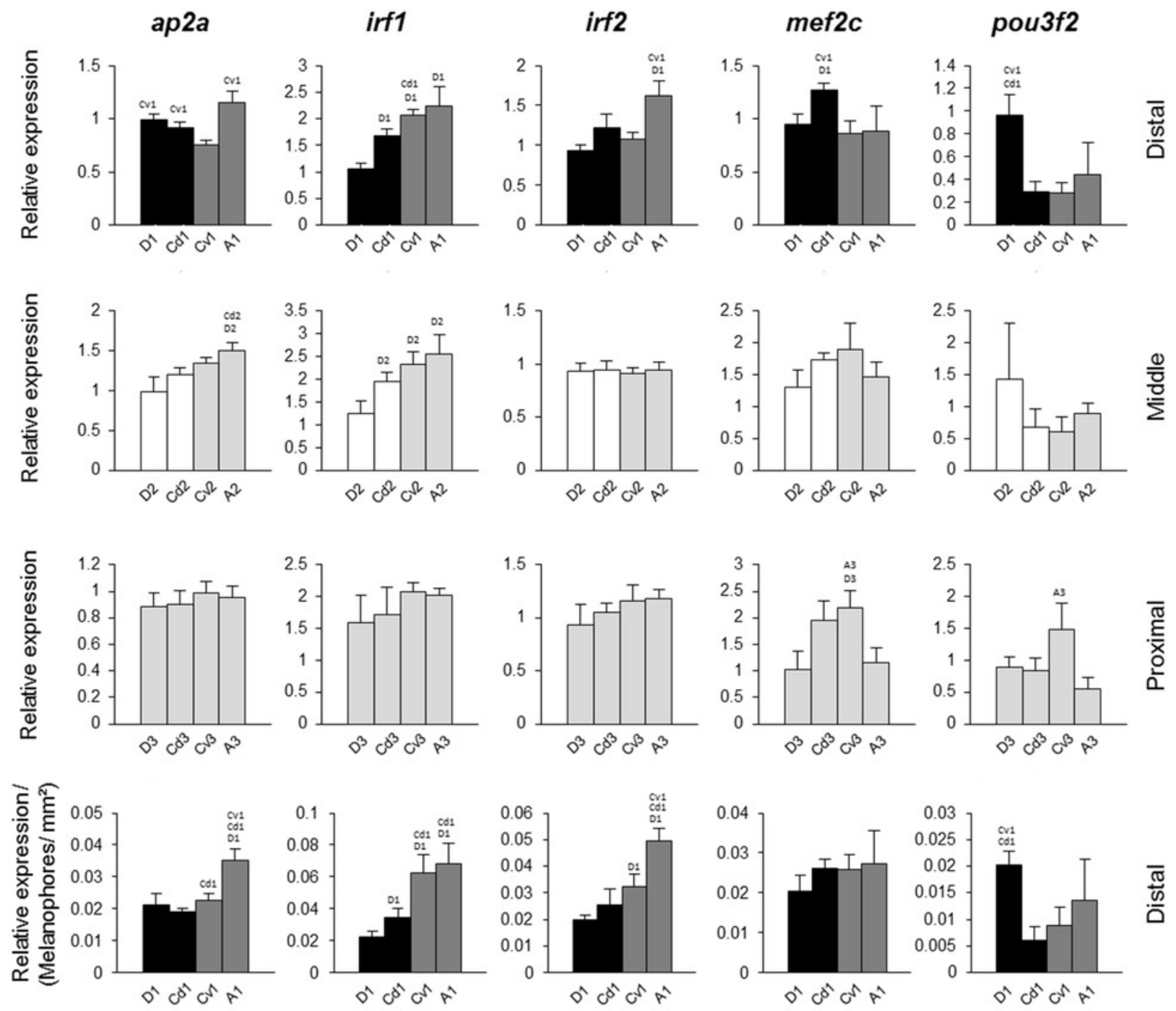

Fin regions

Fin regions

Fin regions

Fin regions

Fin regions 